\title{
Spotlight edition on South America
}

\author{
Ursula Matte $\mathbb{C}^{1} \cdot$ Hugo Peluffo $\mathbb{( i}^{2}$
}

Received: 3 December 2019 / Revised: 3 February 2020 / Accepted: 3 February 2020

C) Springer Nature Limited 2020

South America is a continent of huge social and economic contrasts, both within and between countries. In this spotlight edition, we present an overview of the continent's scientific production on gene and cell therapy. We are delighted to showcase research from multiple countries, namely Brazil, Argentina, Chile, Uruguay, and Colombia. Though more groups are working in this area, the work presented in this Spotlight issue offers a glimpse of research in developing regions, where reagents are mostly imported (and therefore expensive and not readily available) and financial support for scientific activities is often scarce and inconsistent. In spite of that, many groups continue researching in this area, as can be seen in reports describing the evolution of the field of gene therapy in Latin America [1, 2].

As home for about $428,000,000$ people, or a little over $5 \%$ of the world's population, South America will undoubtedly be a market for gene and cell therapy products, once they are commercially approved. It is therefore important to support $\mathrm{R}+\mathrm{D}$ in this field, maintaining a critical mass able to support development and evaluation of these new therapies. Most groups in South America work at or in close partnership with universities, hence scientists are not just involved in basic and/ or translational research, but also helping train new generations of physicians, biomedical scientists, veterinarians, pharmacists, and other health allied professionals who in the future will be responsible for prescribing and administering gene and cellbased therapeutics. The research groups showcased in this issue will be among those leading in this educational challenge and their work shows their international competitiveness.

Ursula Matte

umatte@hcpa.edu.br

1 Post-Graduation Program on Genetics and Molecular Biology, Universidade Federal do Rio Grande do Sul, Ramiro Barcelos, 2350, Porto Alegre 90035-903, Brazil

2 Department of Histology and Embryology, Facultad de Medicina, Universidad de la República, Mataojo 2020, Montevideo 11400, Uruguay and Neuroinflammation and Gene Therapy Laboratory, Institut Pasteur de Montevideo
Multiple challenges exist for the development of the field in our continent, and for the clinical uptake of the new treatments. In particular, the elevated cost of the approved treatments will be a disproportionate burden for the health systems in our region. Moreover, even though some leading groups manage to thrive in the region, the reduced number of trained professionals and their uneven distribution call for dedicated policies to ensure the widespread development and uptake of lifesaving or life-changing therapies tailored to individual patients.

Our fellow researchers accepted our invitation enthusiastically and submitted work in a variety of formats, including original and review articles, and comments on the regulatory aspects and history of gene and cell therapy in particular countries. The topics covered range from cancer to inherited diseases, and also include common disorders such as cardiovascular and Parkinson disease. In terms of gene and cell therapy technology the manuscripts describe viral and nonviral vectors, genome editing, DNA vaccines, chimeric antigen receptor T-cells (CAR-T), induced pluripotent stem cells (iPSC), and adipose-tissue-derived stem cells.

Finally, we would like to thank Editor-in-Chief Prof. Rafael Yáñez-Muñoz for his enthusiastic support of inclusiveness in science. Under his leadership Gene Therapy has promoted the involvement of women and early-career researchers, and ensured representation for people from diverse regional origins. We hope this spotlight edition honors his vision.

\section{Compliance with ethical standards}

Conflict of interest The authors declare that they have no conflict of interest.

Publisher's note Springer Nature remains neutral with regard to jurisdictional claims in published maps and institutional affiliations.

\section{References}

1. Linden R, Matte U. A snapshot of gene therapy in Latin America. Genet Mol Biol. 2014;37(Suppl 1):294-8.

2. Podhajcer O, Pitossi F, Agilar-Cordova E. Gene therapy coming of age in Latin America. Mol Ther. 2002;6:153-4. 